\title{
CONCEPCIONES DE LA DISCAPACIDAD Y NUEVA GENÉTICA

\author{
Un abordaje a partir de un dilema bioético
}

\section{CONCEPTIONS OF DISABILITY AND NEW GENETICS An approach based on a bioethical dilemma}

\author{
Paula Gastaldi ${ }^{1}$ \\ Fecha de envío: 30.06 .2020 \\ Fecha de aceptación: 19.08.2020
}

DOI: https://doi.org/10.37767/2591-3476(2020)17

\begin{abstract}
RESUMEN:
A través de un proceso de fecundación asistida, una pareja de mujeres con sordera ha decidido implantar a la persona gestante un embrión genéticamente predispuesto a desarrollar sordera, seleccionando un donante de esperma que garantice dicha condición por sucesivas generaciones de sordera en su familia. Analizaremos dicho caso como un dilema toda vez que entran en choque dos principios bioéticos: el principio de autonomía de la paciente, por un lado; el principio de no maleficencia, por el otro. El objetivo de este artículo es interrogar acerca de las diversas concepciones de la discapacidad y cómo estás impactan en el modelo de trato brindado a personas con discapacidad. Siendo que no existe unanimidad acerca de cómo debemos conceptualizar la discapacidad y qué implicancias tiene cada modo de conceptualizar a la hora de asumir discusiones filosófico-políticas, abordaremos las distintas concepciones sobre la discapacidad a los efectos mostrar cómo cada concepción razonaría, justificaría y resolvería el dilema moral vinculado a la selección genética.
\end{abstract}

\section{ABSTRACT}

Through a process of assisted fertilization, a couple has decided to implant in the pregnant person an embryo genetically predisposed to develop deafness, selecting a sperm donor that guarantees this condition for successive generations of deafness in their family. We will analyze this case as a dilemma whenever two bioethical principles come into shock: the principle of patient autonomy, on the one hand; the principle of non-maleficence, on the other. The objective of this article is to question about the different conceptions of disability and how they impact the model of treatment offered to people with disabilities. Since there is no unanimity about how we should conceptualize disability and what implications each way of conceptualizing has when assuming philosophical-political discussions, we will approach the different conceptions of disability in order to show how each conception would reason, justify and solve the problem. moral dilemma linked to genetic selection.

1 Abogada (UCC). Magister en Argumentación Jurídica, Universidad de Alicante. Maestranda en Bioética (FLACSO). Doctoranda en Derecho (UNC). Prof. Adjunta Filosofía del Derecho, Facultad de Derecho (UCC). Prof. Asistente Filosofía y Ética de la Educación, Prof. en Cs. Jurídicas (UNC). Miembro integrante del Grupo de Investigación Sesgos implícitos y Decisión Judicial bajo la dirección del Dr. Federico Arena (UBP). Mail: gastaldipau@hotmail.com. ORCID iD: https://orcid.org/0000-0003-3534-9731 
PALABRAS CLAVE: adjudicación judicial; racionalidad material; Derecho a la Salud.

KEY WORDS: Discapacidad; concepciones; fecundación asistida; nueva genética; embriones; sordera.

\section{Introducción. Presentación de la problemática}

El objetivo de este artículo es interrogar acerca de las diversas concepciones de la discapacidad y cómo estás impactan en el modelo de trato brindado a personas con discapacidad. En ese sentido, no existe unanimidad acerca de cómo debemos conceptualizar la discapacidad y qué implicancias tiene cada modo de conceptualizar a la hora de asumir discusiones filosófico-políticas. Aunque abordar esta discusión excede el presente trabajo, sí nos detendremos en las concepciones sobre la discapacidad a los efectos mostrar cómo cada concepción razonaría, justificaría y resolvería un dilema moral vinculado a la selección genética.

En el caso que analizaremos, una pareja de mujeres con sordera ha decidido implantar a la persona gestante un embrión genéticamente predispuesto a desarrollar sordera. Para ello, selecciona un donante de esperma que garantice genéticamente dicha condición por sucesivas generaciones de sordera en su familia. Veremos a dicho caso como un dilema moral toda vez que entran en choque dos principios bioéticos: el principio de autonomía de la paciente, por un lado; el principio de no maleficencia, por el otro.

Para ello, en primer lugar, comenzaremos por identificar las conexiones que median entre la construcción de la categoría "discapacidad" y las concepciones que proponen abordajes sobre cómo debe ser el modo de trato brindado a la misma desde una discusión filosófico política. Veremos, entonces, cuatro propuestas acerca de cómo teorizar la discapacidad: el modelo de la prescindencia; el modelo médico; el modelo médico-social y; el modelo de la diversidad funcional.

En un segundo momento, presentaremos el caso bajo análisis desde la óptica de un dilema moral. Sin embargo, para ello primero comenzaremos por presentar la propuesta principialista de Beauchamp y Childress (1999) y los cuatro principios asumidos por los autores.

Claro está que dicha propuesta no es la única en el campo de la teoría moral respecto a qué decisiones morales debemos tomar en conflictos bioéticos. Por ello, el presente artículo presentará una crítica de parte de otras alternativas morales a dicha propuesta en pos de dilucidar ciertas limitaciones que la misma contendría. De todos modos, parte del objetivo del presente artículo es mostrar cómo el principialismo cuenta con fuerza y aplicabilidad a la hora de resolver dilemas morales. Así, buscará mostrar cómo dichos principios morales son especificados, identificados y presentados bajo una posible lupa de dilema moral.

Indagaremos, entonces, qué solución ofrece cada concepción de la discapacidad y cuál disímiles pueden ser los argumentos esbozados por cada una de ellas a la hora de resolver tensiones al respecto. 


\section{Conceptos y concepciones de la discapacidad}

El objetivo de este apartado es identificar las conexiones que median entre la construcción de la categoría "discapacidad" y las concepciones que proponen abordajes sobre cómo debe ser el modo de trato brindado a la misma.

Es posible distinguir cuatro propuestas sobre cómo teorizar la discapacidad. La primera concepción, que se define como "de prescindencia", considera a la discapacidad como "Una anomalía o estado indeseable para la salud de la persona". En respuesta a esta anomalía, la sociedad decide segregar a las personas con discapacidad, ya sea a través de la aplicación de políticas eugenésicas, o situándolas en el espacio destinado para "anormales" y clases sociales marginadas (Palacios, 2008). Así, esta primera concepción tiene como rasgo conceptualmente relevante y distintivo la comprensión de la discapacidad como una anormalidad física y orgánica notoria y una respuesta de exclusión, eliminación o marginación de las personas con discapacidad.

La segunda concepción, denominada "rehabilitadora" y afincada en el modelo médico, "visualiza la discapacidad como una enfermedad y pregona la rehabilitación como una alternativa superadora de la misma" (Alemany, 2018). Esta segunda concepción tiene como rasgo conceptualmente relevante y distintivo la comprensión de la discapacidad como una enfermedad o patología que debe eliminarse o erradicarse según las posibilidades médicas.

La tercera concepción, denominada "social", considera que la discapacidad es una combinación entre factores médicos en interacción con el entorno. Esta concepción está plasmada en la Convención de Personas con Discapacidad (C.P.D). Su artículo primero reza: "Las personas con discapacidad incluyen a aquéllas que tengan deficiencias físicas, mentales, intelectuales o sensoriales a largo plazo que, al interactuar con diversas barreras, puedan impedir su participación plena y efectiva en la sociedad, en igualdad de condiciones con las demás" ${ }^{\prime 2}$. Así, este tercer modelo tiene como rasgo conceptualmente relevante y distintivo hacer una focalización en las deficiencias en la salud que la discapacidad acarrea, en combinación con una especial interacción entre estas y la sociedad en la cual la persona se desarrolla. Desde esta perspectiva, la manera en la cual se identifica la discapacidad guarda una relación estrecha con el modo como las deficiencias físicas, mentales, intelectuales o sensoriales a largo plazo aparecen condicionadas por el entorno y, por tanto, el dato acerca de la interacción es el rasgo característico. La Organización Mundial de la Salud (en adelante, O.M.S) entiende a la discapacidad como:

“... un término general que abarca las deficiencias, las limitaciones de la actividad y las restricciones de la participación. Las deficiencias son problemas que afectan a una estructura o función corporal; las limitaciones de la actividad son dificultades para ejecutar acciones o tareas, y las restricciones de la participación son problemas para participar en situaciones vitales. Por consiguiente, la discapacidad es un fenómeno complejo que refleja una interacción entre las características del organismo humano y las características de la sociedad en la que vive." ${ }^{\prime 3}$

Como vemos, la OMS entiende por deficiencia a los problemas que afectan a una estructura o función corporal. Es decir, la deficiencia, ya sea física, mental, intelectual o senso-

$2 \mathrm{El}$ resaltado con cursiva me pertenece.

3 Recuperado el 20/11/2019 de http://www.who.int/topics/disabilities/es. 
rial que se presenta en el organismo a largo plazo, es el rasgo médico; mientras que la interacción con el entorno puede presentar las siguientes manifestaciones: por un lado, limitaciones de la actividad, entendidas como las dificultades para ejecutar acciones o tareas; por otro lado, las restricciones de la participación entendidas como problemas para participar en situaciones vitales. En estas limitaciones y restricciones estaría el rasgo social que remarca el modelo social de la discapacidad.

La cuarta concepción, relativa a la diversidad funcional, sostiene que el modelo social ha mantenido ciertas aspiraciones de "normalidad", lo que tornaría necesaria su superación (Romañach, 2008). Así, esta última concepción tiene como rasgo conceptualmente relevante y distintivo proponer un abordaje de la discapacidad que abandona la óptica médica y apuesta por identificar el origen de los aspectos problemáticos de este fenómeno ni más ni menos que en el trato discriminatorio que reciben los sujetos que lo padecen. De hecho, desde esta concepción, se argumenta que el propio criterio de qué debe ser considerado deficiencia funcional está construido por la manera que se menosprecia la discapacidad. El fundamento de esta concepción se basa en la aserción según la cual la diversidad en el funcionamiento del cuerpo es inherente al ser humano, por lo que esta diversidad debería recibir una valoración positiva (Morales Aguilera y Vallés González, 2013).

Presentados, entonces, los modos en que cada concepción identifica los rasgos conceptualmente relevantes y distintivos respecto al trato brindado hacia la discapacidad, podemos ahora indagar las clases de conexiones que se dan entre cada enfoque y la manera conceptualizarlo. De esta manera, es posible distinguir tres ópticas para conceptualizar la discapacidad. La primera óptica es médica (en adelante, 01), utilizada tanto por la concepción de la prescindencia como por la rehabilitadora. Según 01, a los efectos de definir la categoría de "discapacidad" es necesario remitirse a cierta enfermedad, de naturaleza prolongada y/o perdurable. La segunda es la óptica médico-social (O2), utilizada por la concepción social. Esta $\mathrm{O} 2$ sostiene que la definición misma de discapacidad se basa en una relación dada entre cierta deficiencia en la salud y el entorno ${ }^{4}$ social en el que la persona se desarrolla. Esta óptica pone especial atención en el entorno social en tanto éste condiciona y levanta barreras a personas con discapacidad. Así, por ejemplo, personas con talla baja podrían llegar a ser consideradas personas con discapacidad si el entorno imposibilita el acceso al transporte público (y las demás estructuras de funcionamiento social) en razón de su altura. La tercera es la óptica social (O3), utilizada por la concepción de la diversidad funcional. Desde esta óptica la definición de discapacidad depende exclusivamente de una construcción social de qué se considera disvalioso y, por tanto, es menospreciado.

De esta manera, mientras que la $\mathrm{O} 1$ reposa en un aspecto de naturaleza psicofísica y la $\mathrm{O} 2$, de base médica, vinculando a la discapacidad con el entorno (por ello la he denominado médica- social), O3 elimina esa base médica. Sin embargo, considero que la O2, defendida por la concepción social, la única comprometida con un abordaje mixto de la discapacidad, poniendo la nota distintiva tanto en las cuestiones médicas como en el entorno social. Veremos, al concluir este trabajo, las razones en las que descansa esta defensa.

\section{Bioética: el principialismo de Beauchamp y Childress}

4 Por entorno entiendo hábitos (de insolidaridad, por ejemplo), prácticas, instituciones, normas, costumbres, discursos. En este sentido, engloba la noción de interacción. 
El presente artículo recorre una fundamentación respecto a cómo resolver un caso bioético partiendo por abordar un modelo teórico de justificación que permita valorar éticamente la situación planteada. Claro está que no es posible unificar el campo de la bioética en una sola teoría moral. Si nos preguntamos cuál es la teoría ética para la bioética, correremos con la misma suerte que las teorías morales en general: tendremos un abanico de discusiones morales previas a consolidar un instrumento válido para analizar los casos planteados. Sin embargo, a los efectos del presente artículo nos basaremos en la teoría principialista de Beauchamp y Childress (1999)5, quienes han propuesto los siguientes cuatro principios: a) el principio de respeto de la autonomía; b) el de no maleficencia; c) el de beneficencia y d) el de justicia. Dichos principios se presentan como una proposición abstracta que engloba o representa algún valor moral y que aporta un fundamento a la conducta esperada por el agente. En este sentido, los principios son la base para una decisión moral, por lo que norman la conducta del agente, en este caso médicos y médicas, a la hora de resolver tensiones éticas. Ahora bien, ¿qué propone cada principio? Por el momento, nos conformamos por presentar las siguientes consideraciones en torno a cada uno de ellos:

a) el principio de respeto de la autonomía indica que el agente debe tener en cuenta la decisión autónoma del paciente en lo que respecta a su salud, entendiendo como tal aquella que se decide intencionadamente, con cabal conocimiento de sus implicancias y sin influencias externas que vicien la voluntad;

b) el de no maleficencia impone al agente el deber general de "no dañar a otro", es decir, cuenta con una formulación deontológica en negativo que obliga a abstenerse de concretar intencionalmente alguna práctica dañosa.

c) el de beneficencia pone en cabeza de los profesionales de la salud la obligación de tomar decisiones y acciones en pos del bienestar del paciente, por ejemplo, amputar una pierna frenar la dispersión de un tumor maligno.

d) el de justicia impone que las personas deben ser tratadas de modo igual y aborda los problemas de distribución de los recursos y el acceso a la justicia sanitaria.

Es loable exponer que no sólo existe el principialismo de Beauchamp y Childress como la propuesta de encuadre respecto a las discusiones éticas alrededor de la conducta esperable de médicos y médicas en determinada situación. Hay otras concepciones que se proponen alternativas y superadoras. Así, por ejemplo, lo que se conoce como ética de la virtud ha calado en una crítica sensata al modelo principialista, en donde pone en el centro de la discusión moral a la categoría virtud, que dotaría de sentido la práctica médica orientando las decisiones morales. Propone, entonces, abandonar el término "deber" sobre el cual está erigido el principialismo y reparar en el carácter del sujeto moral. El eje está en potenciar el carácter humano a través de las virtudes necesarias para iluminar toda decisión moral. Tal como ha sido entendido, supone que el quehacer sanitario médico parece estar atravesado por otras realidades que al principialismo de Beauchamp y Childress y su final propuesta basada en el seguimiento de reglas, no alcanzaría a dilucidar. Así, se ha asumido que la ética basada en las virtudes podría recuperar el carácter emocional de la práctica médica, siendo esta una razón para otorgarle validez de aplicación (Díaz García, 2009).

Sin embargo, tal como han analizado los autores, aunque la ética de la virtud puede

5 Ello se debe a una decisión tanto teórica como metodológica, ya que el presente artículo pretende rescatar la validez de dicha propuesta a la hora de resolver un dilema moral, toda vez que, a partir de la identificación e especificación de los principios morales en juego, podemos sopesarlos en proceso deliberativo que resuelve el dilema moral a través de la ponderación de dichos principios. 
afianzar la propuesta principialista, preocupándose respecto a cómo guiar la conducta concreta a partir del carácter del agente moral, la ética de carácter no puede remplazarla. Ello, por cuanto, la ética de la virtud no ofrecer una explicación adecuada de porqué un determinado acto debe ser considerado incorrecto desde el punto de vista moral. Así, puede la persona virtuosa actuar incorrectamente. En este sentido, podría pensarse que son complementarias, pero nunca la ética de la virtud podría reemplazar a la ética de corte principialista expuesta por los famosos autores.

Ahora bien, la gran crítica a dicha propuesta es cómo resolver una tensión o contradicción entre los principios. ¿Existe una jerarquía entre ellos? Aunque ha habido intentos por jerarquizar uno por sobre otro $y$, ante un choque siempre priorizar alguno de ellos; lo cierto es que eso conlleva aparejada una rigidez que dota de sentido a una crítica sensata. La propia propuesta de Beauchamp y Childress, en cambio, consiste en reconocer distintos aspectos claves hacia la concreción de los principios cuando estamos frente a un dilema moral.

Asumiendo que el dilema moral aparece cuando no existe un único principio, jerárquicamente superior, que resuelve los conflictos, siguiendo la línea de la propuesta del filósofo inglés Ross (2002), aunque las obligaciones que emergen de dichos deberes son prima facie, estas sólo se mantienen mientras no entran en conflicto entre sí. Es decir, al entrar en conflicto la situación debe resolverse haciendo una evaluación y ponderación de las obligaciones contrapuestas en esa situación en particular. En una ponderación entre las diferentes obligaciones prima facie que están en conflicto, los principios - a priori generales y abstractos - deben ser traducidos en normas particulares concretas. De esta manera, ponderar exige también especificar, es decir, reducirlos a reglas menos indeterminadas. En este proceso de especificación, es posible identificar que no todos los principios nombrados entrarían en juego en un caso concreto. Así las cosas, el primer paso es especificar el alcance de los principios en el caso concreto para posibilitar determinar cuáles de ellos entraría en juego y dónde estaría situado el dilema moral. Luego, para posibilitar una resolución de dicho dilema, procede la ponderación, esto es, sopesar cada principio y deliberar cuál tiene más peso en la situación concreta.

En este sentido, el presente artículo ofrece una muestra de dicho procedimiento, a saber: especificar la presencia de cada principio para dar cuenta de porqué entrarían en colisión dos de ellos para, finalmente, resolver el dilema moral a través de ponderar su sentido y alcance a la luz de las distintas concepciones de la discapacidad.

\section{Un dilema moral: la presentación de un caso.}

En Contra la Perfección, Michael Sandel (2007) relata un caso famoso: en el año 2002, S. y C., una pareja de mujeres sordas, se someten a un proceso de inseminación artificial para el que buscan como donante de esperma a una persona con cinco generaciones de sordera en su familiar. Así, con esta elección lograban que su descendencia tuviera necesariamente el gen de la sordera. S. y C., finalmente, tuvieron un hijo sordo a partir de la fertilización asistida. Este caso ha llevado a un profundo debate. Las madres han sido atacadas duramente por la opinión pública de haber elegido que su hijo tenga una discapacidad. Sin embargo, su defensa ha sido terminante, "Ser sordo es solo una forma de vida", dijo C. (Sandel, 2007). "Nos sentimos completas como personas sordas y queremos compartir los maravillosos aspectos de nuestra comunidad sorda, un sentido de pertenencia y conexión con los niños" (Sandel, 2007: 7). Es decir, desde la mirada de las 
madres, la sordera no debe asociarse a algo negativo, sino por el contrario es una concepción de vida y la unión a un grupo de pertenencia.

Sobre el caso Sandel se pregunta: ¿Está mal hacer que un niño sea sordo por diseño? Si es así, ¿qué lo hace mal: la sordera o el diseño? Aunque la pregunta que dispara Sandel despierta gran interés - y es, sin duda, la pregunta central -, en esta oportunidad pretendo abordar el caso comprendiéndolo bajo de la lupa de un dilema moral. Se presentan dos deberes en conflicto: por un lado, el deber de no maleficencia que obliga a abstenerse de llevar a cabo una práctica que dañaría la salud y aptitudes físicas del hijo/a; por otro lado, el deber de respeto por la autonomía de las madres, quienes han expresado un deseo de que su hijo/a tenga sordera. ${ }^{6}$

Tal como hemos presentado anteriormente, el dilema moral aparece toda vez que asumimos que no existe un único principio, jerárquicamente superior, que resuelve los conflictos. Cabe preguntarse, ¿cuál es la decisión que debieran tomar las/os médicos/as frente a este dilema?

Lo primero que debemos hacer es especificar el alcance de los principios en el caso concreto para posibilitar determinar cuáles de ellos entraría en juego y dónde estaría situado el dilema moral. Veamos.

El principio de autonomía está en juego toda vez que la pareja de mujeres ha expresado su decisión de implantar un embrión con fertilización asistida. Por su parte, el principio de no maleficencia estaría en juego toda vez que dicho procedimiento podría traer una consecuencia indeseada - según la concepción de la discapacidad desde la cual se lo aborde. Siendo que las madres han decidido que el embrión implantado tenga como condición genética la sordera, habría que indagar si dicho procedimiento es permisible a la luz del principio en cuestión. En cambio, el principio de beneficencia no entraría en el caso concreto. Ello, por cuanto, si entendemos que beneficencia impone la obligación a médicos y médicas de tomar decisiones y acciones en pos del bienestar del paciente, por ejemplo, aquí debemos considerar a las mujeres como las pacientes y, por tanto, no aplicaría una obligación moral formulada en positivo que contradiga la decisión autónoma que ellas tomaron.

Por último, en cuanto al principio de justicia, y derivado de entender a la pareja de mujeres como las pacientes, en este caso el principio de justicia no estaría en juego toda vez que no se discute respecto a la imposibilidad del acceso a un procedimiento médico sobre la base de problemas de recursos o justicia sanitaria. Una aclaración: las mujeres que pretenden acceder a una fertilización asistida cuentan con discapacidad. A la luz de nuestro ordenamiento jurídico, los derechos de personas con discapacidad al acceso a la salud deben ser considerados amplios, sobre la base de una asignación mayor de recursos que a personas sin discapacidad, toda vez que -para dotar de vida digna- es necesario elevar los recursos sanitarios en pos de lograr el bienestar de pacientes. Argentina pone

6 En Argentina, la ley $\mathrm{N}^{\mathrm{a}} 26.862$ de "Acceso integral a los procedimientos y técnicas médico-asistenciales de reproducción médicamente asistida" y su
decreto reglamentario Nro.956/2013, tiene por objeto garantizar el acceso integral a los procedimientos y técnicas médico asistenciales de reproducción
asistida $\left(\mathrm{cfr}\right.$. art. $1^{\circ}$ ), tanto de baja como de alta complejidad $\left(\mathrm{cfr}\right.$. art. $2^{\circ}$ ). Por su parte, tienen derecho a acceder toda persona mayor de edad que haya
explicitado su consentimiento informado ( $\mathrm{cfr}$ art. $7^{\circ}$ ). Asimismo, las obras sociales y entidades de medicina prepaga tienen el deber de incorporar dicho
procedimiento a las prestaciones obligatorias a brindar a sus afiliados y se determina su inclusión en el Programa Médico Obligatorio, con los criterios y
modalidades de cobertura que establezca el Ministerio de Salud como autoridad de aplicación (cfr. arts. $3^{\circ}$ y $8^{\circ}$ ). Por su parte, sus disposiciones son de orden
público y de aplicación en todo el territorio de la República (cfr. art.10). Para determinar cuáles son los "embriones viables", es decir, "aquellos que pueden
ser transferidos al útero de la mujer, en virtud de estudios previos que así lo determinan" (cfr. art. 14), se utiliza el Diagnóstico Genético Preimplantatorio. 
en cabeza del Estado - y las obras sociales - la cobertura integral de estos procedimientos para personas con discapacidad. De todas maneras, y si de nuestra legislación se trata, también existe una ley de acceso a los procedimientos de fertilización asistida que declara la obligación del Estado y las obras sociales a la cobertura integral de estos procedimientos, ya sea personas con discapacidad o personas sin discapacidad (Ley $\mathrm{N}^{\circ}$ 28.862). ${ }^{7}$. De esta manera, y a los efectos del presente artículo, no entraría en juego el principio de justicia toda vez que no habría una imposibilidad de acceso al tratamiento que se funde en cuestiones de recursos.

Una vez especificada esta contradicción entre el respeto de la autonomía y el principio de no maleficencia, en pos de resolver dicha tensión entre dichos principios resta ponderar el alcance y sentido de cada uno de ellos a la luz del caso concreto. El primer principio, entonces, obliga a los médicos a tomar en cuenta la decisión libre de las pacientes; el segundo principio, a diferencia del principio de beneficencia, reposa sobre el deber general de "no dañar a otro", es decir, cuenta con una formulación deontológica en negativo que obliga a abstenerse de concretar intencionalmente alguna práctica dañosa. Veremos qué argumentos hay para sostener cómo deben proceder los médicos en este caso, haciendo una evaluación y ponderación de las obligaciones contrapuestas en esa situación en particular.

\section{El principio de respeto por la autonomía del paciente y su análisis desde el consentimiento.}

El principio de respeto por la autonomía consiste en partir de la voluntad del paciente a los efectos de tomar cualquier decisión médica que pueda afectar su salud. En el caso que analiza Sandel (2007), en pos de cuestionar el alcance del principio de autonomía, tomamos como paciente a la persona gestante que debe ser auxiliada mediante un procedimiento médico para tener un/a hija. Ahora bien, a la luz de este artículo, cuando refiero a autonomía incluyo dentro de ésta la autonomía procreativa. Esta aclaración se realiza ya que podría objetarse que, en general, hablamos del principio de autonomía del paciente cuando hay un rasgo de la salud que podría verse afectado y aquí no es la salud de las madres la que podría verse afectada sino la salud de su hijo. En esta línea, alguien podría sostener que, para que la autonomía de las madres "en tanto pacientes" se vea comprometida, necesariamente lo que debe estar en cuestión es un aspecto de su salud vinculado al procedimiento de inseminación. De todas maneras, y desde un sentido amplio del término salud, su autonomía "procreativa" está en juego y se verá afectada la salud en caso de recibir una negativa médica de llevar adelante un procedimiento de inseminación.

A esta altura podemos comprometernos a sostener que existe un deber médico de preservar y hacer valer la decisión autónoma que toma la paciente. Ahora bien, para considerar que la decisión de un paciente es autónoma debemos asegurarnos que procede de

\footnotetext{
7 El artículo 8 de la ley $\mathrm{N}^{\circ} 28.862$ sostiene: "Cobertura. El sector público de salud, las obras sociales enmarcadas en las leyes 23.660 y 23.661 , la Obra Social del Poder Judicial de la Nación, la Dirección de Ayuda Social para el Personal del Congreso de la Nación, las entidades de medicina prepaga y las entidades que brinden atención al personal de las universidades, así como también todos aquellos agentes que brinden servicios médico-asistenciales a sus afiliados independientemente de la figura jurídica que posean, incorporarán como prestaciones obligatorias y a brindar a sus afiliados o beneficiarios, la cobertura integral e interdisciplinaria del abordaje, el diagnóstico, los medicamentos y las terapias de apoyo y los procedimientos y las técnicas que la Organización Mundial de la Salud define como de reproducción médicamente asistida, los cuales incluyen: a la inducción de ovulación; la estimulación ovárica controlada; el desencadenamiento de la ovulación; las técnicas de reproducción asistida (TRA); y la inseminación intrauterina, intracervical o intravaginal, con gametos del cónyuge, pareja conviviente o no, o de un donante, según los criterios que establezca la autoridad de aplicación. Quedan incluidos en el Programa Médico Obligatorio (PMO) estos procedimientos, así como los de diagnóstico, medicamentos y terapias de apoyo, con los criterios y modalidades de cobertura que establezca la autoridad de aplicación, la cual no podrá introducir requisitos o limitaciones que impliquen la exclusión debido a la orientación sexual o el estado civil de los destinatarios (...)".
} 
los valores y creencias propios de dicha persona, se basa en una información y comprensión adecuadas y no viene impuesta por coacciones internas o externas.

Aquí debemos indagar la validez de la decisión autónoma que han tomado las madres. Comencemos por advertir, entonces, la necesidad de analizar las condiciones que establece Brock (1994) para el consentimiento válido. Tal como sostiene el autor, las condiciones son tres. La primera, la competencia, establece el requerimiento que las pacientes sean competentes para que el consentimiento sea vinculante. Ahora bien, tal como se advierte, no es una tarea simple determinar cuándo el paciente ha dado integro consentimiento a un tratamiento o intervención. Se ha sostenido que se debe asegurar un balance aceptable entre permitir a las personas decidir por sí mismas, por un lado, y protegerlas de las consecuencias dañinas de sus propias decisiones cuando su capacidad de decisión está seriamente limitada o sea deficiente, por el otro. De esta manera, considero necesario indagar acerca de diferentes criterios de competencia que van desde el criterio menos estricto al más estricto. Podemos, o bien reparar en la habilidad para expresar una preferencia, o bien utilizar criterios para evaluar el contenido de la decisión del paciente y, por último, utilizar criterios que evalúan la naturaleza de la comprensión y del razonamiento del paciente. Este último criterio de competencia se centra en el proceso de la toma de decisión, más que en el hecho de si el paciente meramente hizo una elección o en el contenido de su elección. En el caso bajo análisis, considero necesario detenernos sobre este último criterio y considerar como válido el consentimiento dado por las madres toda vez que, del relato de los hechos, no surge que no comprendan las consecuencias de implantar un embrión que tendrá sordera. El segundo criterio es la voluntariedad. Para que el consentimiento a una toma de decisión sea respetable, ésta debe ser voluntaria o tomada libremente. En este sentido, cabe advertir que sólo sería aceptable una adecuada persuasión racional, mediante la cual el médico brindara información acerca de los distintos las consecuencias de llevar adelante la fertilización, así como de sus beneficios e inconvenientes, y ofreciera su posición personal al respecto. En este sentido, el caso muestra una clara voluntariedad por parte de las madres. Así, aparece ligado el tercer criterio: la comprensión informada. El objetivo del requerimiento de que el consentimiento sea informado consiste en que los pacientes alcancen una suficiente comprensión de su condición y de sus posibles tratamientos para que ellos puedan establecer qué tratamiento quieren afrontar. Aquí, sin dudas, existe una compresión informada por parte de ambas pacientes.

Dicho esto, el principio de autonomía está presente en el caso. A su vez, si a esta altura alguien pretendiera atacar que el principio de autonomía no juega toda vez que las pacientes están tomando una decisión sobre un embrión "persona por nacer", advierto que el embrión es vida humana pero no cuenta con el status de persona humana. ${ }^{8}$ Por su parte, respecto a las consecuencias de esta fecundación que será el nacimiento de una persona con discapacidad, vale aclarar que allí - justamente - ya entraría el principio de no maleficencia ${ }^{9}$. Veremos cómo se resuelve el alcance de dicho principio a continuación.

8 Aquí corresponde hacer una aclaración: a los efectos del presente trabajo se considera que los embriones no son persona humana. Aquí no ingresaría la
discusión acerca del status moral del embrión. Por el momento, el argumento puede ser que hasta que no sean implantados no cuentan con status moral de
protección jurídica independiente, sino dependientes de la autonomía de la paciente o persona gestante que tiene interés en ser implantada. Ver nota 10 .
9 Puede haber una manera no conflictivista de reconstruir este caso. Si el deber de no maleficencia tan sólo consiste en garantizar una inseminación segura,
sin importar el contenido del material genético inseminado, entonces el médico no infringirá este deber, aun cuando actúe a sabiendas de que la persona
que será gestada padecerá de sordera. En este caso, el deber del médico se circunscribiría a garantizar la salud de la persona inseminada, no la salud de quien
nacerá como fruto de esta inseminación. Ulteriormente, si alguien debiera responder por esta decisión, no es el médico, sino las madres. De todas maneras,
entiendo que el deber del médico debe abarcar las consecuencias de las prácticas que imparte y no solo la viabilidad y éxito de la práctica en sí misma. 


\section{El principio de no maleficencia}

Retomemos las palabras de las mujeres, "Ser sordo es solo una forma de vida"; "Nos sentimos completas como personas sordas y queremos compartir los maravillosos aspectos de nuestra comunidad sorda, un sentido de pertenencia y conexión con los niños" (Sandel, 2007: 7). De esta manera, el argumento de ellas esboza que la sordera no debe ser considerada una discapacidad, sino una diversidad. Sin embargo, el presente artículo comenzó mostrando distintas concepciones de la discapacidad y advirtió la existencia de un desacuerdo desde el momento mismo de abordar un concepto de discapacidad. Vale aclarar que todos los conceptos que allí se abordaron son normativos: no sólo describen qué es discapacidad sino que van de la mano de una propuesta de cómo debe ser tratada la discapacidad. Ahora bien, en pos de lograr articular una respuesta en torno a la presencia del principio de no maleficencia en el caso bajo análisis, propongo detenerme en la noción de secuela: es decir, ahondar en la sordera como una consecuencia médica de la decisión que han tomado las pacientes sobre el hijo por nacer e indagar qué tipo de respuesta daría cada concepción de las plasmadas y cómo ello impacta en la manera en la que se identifican los rasgos relevantes del concepto de discapacidad..$^{10}$

Secuela, en su sentido etimológico, proviene del latín "sequela" que refiere a aquello que sigue a algo. En este sentido, entendemos a la secuela como el resultado que conlleva un hecho determinado.

Comenzando por la primera concepción, la de la prescindencia, la persona con discapacidad es considerada anormal por razones exclusivamente naturales/ biologicistas. Tal como he sostenido, esta concepción suele poner a PDC en espacios marginados, con una fuerte dependencia hacia sus cuidadores, marcada por la asistencia por parte de su núcleo afectivo o familiar. Palacios (2008) nos recuerda que esta concepción está vigente, por ejemplo, cuando se discute acerca del aborto y cuestiones relativas a los análisis genéticos prenatales que buscan detectar ciertas discapacidades; la Nueva Genética y el descarte de embriones con discapacidad, entre otros. En esta línea se ha discutido la ética utilitarista de Singer, y ha sido rechazada por el colectivo de personas con discapacidad, desde que el autor sostiene que no sólo los fetos sino también los bebés con discapacidad pueden ser evitados. En febrero de 2003, apareció publicado en el magazine del New York Times un relato que causó un notable impacto: "Unspeakable Conversations", de Harriet McBryde Johnson quien cuenta con una discapacidad y relata una conversación con Singer. Baena (2008) traduce la conversación y narra las palabras de Harriet:

"Él insiste en que no me quiere matar. Simplemente piensa que habría sido mejor, en conjunto, haber dado a mis padres la opción de matar al bebé que una vez fui, y, también, permitir que otros padres pudieran matar a futuros bebés parecidos. De ese modo, se evitaría el sufrimiento que suponen vidas como la mía, y se verían satisfechas las razonables preferencias de los padres por otro tipo de niño. No es nada personal. No tendría por qué sentirme amenazada" (Baena, 2008: 3).

Las razones de porqué Singer considera la eugenesia como un camino deseable se debe a que considera que ciertas discapacidades generan que la persona no sea considerada persona, ya que no tiene conciencia de sí. Sin embargo, tal como lo presenta McBryde Johnson, la propuesta de Singer nada tiene que ver con que si la persona (niña o niño) puede tener conciencia de sí y es un abordaje de la discapacidad como una anomalía

10 Advierto que para las cuatro concepciones la sordera es una discapacidad, pero discurren acerca de qué trato se le debe brindar a la misma. El argumento que esbozaron las madres podría encuadrarse en la cuarta concepción: la de la diversidad funcional. 
indeseable, tanto para los padres como para la niña o niño. Ello, por considerar que la persona con discapacidad no podrá alcanzar la felicidad.

Por su parte, la concepción médica, al conceptualizar la discapacidad desde 01, sostiene que la misma es un problema de salud. Por tanto, el modelo cuenta con la tendencia a emparentar discapacidad con enfermedad. En este sentido, la discapacidad es originada en una enfermedad o en una lesión. Ahora bien, desde esta óptica, ¿cuál sería la diferencia entre enfermedad y discapacidad? Tanto la enfermedad como la discapacidad representan una deficiencia o desviación de alguna norma en el estado biomédico del individuo. Sin embargo, la discapacidad se presenta en el organismo como una pérdida o anormalidad de una estructura o función psicológica, fisiológica o anatómica, que conlleva a la exteriorización de un estado patológico que refleja las perturbaciones a nivel del órgano. Y dicha exteriorización debe presentarse de manera prolongada en el tiempo.

Recordemos que, tanto la concepción de la prescindencia como el modelo médico, coinciden en la óptica de conceptualizar a la discapacidad, 01, en donde prima la óptica médica. De esta manera, desde ambas concepciones, la secuela es la expresión misma de la deficiencia en la salud. Así, mientras la concepción de la prescindencia excluye o prescinde de personas con discapacidad; la concepción médica defiende que se debe trabajar sobre la secuela, eliminándola en lo posible. El modelo médico pretende rehabilitar la salud de personas con discapacidad. Ahora bien, como respuesta exclusiva de trato hacia la discapacidad, la concepción médica propone la rehabilitación y, por tanto, el Estado debe garantizar el acceso a la salud de personas con discapacidad. Sin embargo, esto implica presuponer que la "rehabilitación" es el único modo de bienestar: la salud es un derecho, no un deber. Si la persona con discapacidad desea intentar algún mejoramiento de su salud, ello debe estar garantizado. Pero, suponer que todos los problemas derivan y son el estado de salud es (en el mejor de los casos) desconocer por completo la problemática.

Desde ambas, entonces, el accionar de las madres no es permisible toda vez que están decidiendo hacer el mal a su hijo. Por razones biológicas, carecer del sentido del oído es indeseable. Se perjudica al hijo desde el momento en el que se elige que carezca de un sentido básico para el desarrollo. El parámetro médico en ambas concepciones juega como un parámetro perfeccionista acerca de lo que es deseable a nivel biológico. De esta manera, las razones que ofrecen ambos modelos son incompatibles con un reconocimiento hacia la discapacidad que enfatice el rol de la sociedad en el desarrollo y vida de las personas con discapacidad. Veamos la propuesta de las siguientes dos concepciones.

La tercera concepción, la del modelo social, utiliza una óptica médico-social (O2), proponiendo otra manera de abordar la propia noción de secuela. Tal como hemos dicho, la O2 sostiene que la definición misma de discapacidad se basa en una relación dada entre cierta deficiencia en la salud y el entorno social en el que la persona se desarrolla. Esta óptica pone especial atención en el entorno social en tanto que condiciona y pone barreras a personas con discapacidad. La secuela no es la expresión misma de la deficiencia, sino que es la desventaja asociada a dicha deficiencia en la salud, en tanto impedimento de funcionalidad que acarrea la discapacidad. Desde este modelo, y enfatizando en la desigualdad que la diferencia acarrea, el trato brindado a la discapacidad debe incluir distintas medidas, a saber: una protección integral que garantice vivienda, acceso al trabajo, pensiones no contributivas, accesibilidad en los espacios sociales y, también, acceso a prestaciones médicas en el mejoramiento del estado de salud. Quiero ser clara: no 
significa que la concepción social no pretenda aspirar al mayor bienestar posible de la persona con discapacidad en términos de salud, sino implica que no debemos presuponer que la "rehabilitación" es el único modo de bienestar y debe considerarse la decisión de la persona con discapacidad en relación a qué decide sobre su salud.

La concepción de la diversidad funcional cuestiona el foco que continúa manteniendo el modelo social. En este sentido, advierte que conserva cierta tendencia a mantener la normalización del modelo médico, justamente por entender a la secuela como una combinación de factores (O2). Desde la óptica de la diversidad, la secuela es exclusivamente social. Ello, por cómo la sociedad menosprecia la diversidad funcional. La diversidad funcional se presenta como inherente a la propia naturaleza humana, ya que nuestro cuerpo y nuestra mente (al igual que sucede con las capacidades físicas, mentales y sensoriales) no cuentan con la misma funcionalidad a lo largo de la vida, así, por ejemplo, la niñez cuenta con cierta diversidad funcional comparada con la juventud o la adultez, y ésta última a la vejez. En este sentido, la sociedad, a la luz de ciertos parámetros "deseables" menosprecia la diversidad. Pero, no sólo la menosprecia, sino que la condiciona. Incluso el discurso médico conserva una "patologización" y rotula de "deficiente" a la luz de un discurso normalizador (Eroles, 2008). La propuesta para lograr dirimir la secuela es, entonces, erradicar el menosprecio y compresión misma de la discapacidad y hacer foco en cómo revertir el trato hacia la diversidad funcional. En este sentido, el reconocimiento de la discapacidad debe cambiar. Para ello, se propone incluso una reconstrucción de la idea de dignidad humana, y una invitación de dar voz al colectivo y a la persona con discapacidad respecto a su propio desarrollo y proyecto de vida.

Ahora bien, respecto a estas dos últimas concepciones, ¿qué respuesta daría cada concepción acerca de la selección genética efectuada por estas madres? Considero que ambas concepciones lo considerarían permisible. Sin embargo, reconozco que una primera lectura haría pensar que la concepción médico social, al conservar el parámetro médico, diría que no es permisible. Pero si esa es la postura desde el modelo social, implicaría que, en caso de poder elegir, la discapacidad no es deseable toda vez que parece infringirle un daño físico a una persona. ${ }^{11}$ Ahora bien, así puesto podría esta concepción parecerse a una concepción de la prescindencia y admitir, entonces, el desecho de embriones con discapacidad o el aborto por exclusivas razones eugenésicas. ${ }^{12}$ Pensemos: en el caso del desecho de embriones por discapacidad. ¿Es lo mismo poder elegir un embrión que tenga discapacidad que poder desechar embriones que tengan discapacidad? Aunque esta pregunta nos lleva a la discusión compleja acerca de la selección genética a nivel general, reconociendo casos de pacientes que buscan elegir etnicidad, color de ojos, y demás cuestiones estéticas de una persona "valoradas" en un sistema normativizado como el que vivimos, para salir del brete es necesario - considero - detenerse a cuestionar la motivación que existe atrás de cada caso de selección genética. Mientras que el modelo de la prescindencia (y también el médico) defienden parámetros perfeccionistas acerca de la biología humana, buscando erradicar las diferencias que la discapacidad conlleva, por el contrario, el modelo médico social a la hora de abordar discapacidad conserva el

\footnotetext{
11 Parece relevante detenerse a indicar que gran parte de las discapacidades son indeseadas, no como el caso bajo análisis que fue buscada por las madres. Me refiero a que no son planeadas: refieren a azar natural (Rawls, 1976), accidentes, falta o carencia de bienes materiales indispensables para el desarrollo, cuestiones genéticas, enfermedades prolongadas, etc.

12 En el presente trabajo no nos detendremos a analizar aborto por razones eugenésicas. Sin embargo, y como advertí en la nota 7, podría sostenerse que vida humana no goza por sí solo de status moral de persona humana. Asimismo, entre quienes hablan del estatus moral del feto y aun así defienden el aborto tenemos a Warren (1995) y Thomson (2001). Sólo para resumir su postura, recordemos que Warren sostiene "que aun si las personas potenciales tienen prima facie un derecho a la vida, el derecho a la integridad y autonomía corporal de la mujer, que es una persona actual, siempre prevalece". Por su parte, Thomson sostiene que (aun asumiendo el estatus moral del feto) no estamos obligadas moralmente a dar o mantener con vida a un tercero.
} 
dato médico a los efectos de reconocer cómo debe ser el trato brindado a la discapacidad desde una discusión normativa pero no lo hace a los efectos de clasificar como indeseable dicho estado de salud. Así, desde los primeros dos modelos desechar embriones por discapacidad y no permitir el implante de embriones que tendrán discapacidad están justificados desde el momento que es deseable no tener inconvenientes en la salud. Como Peter Singer ha sostenido, no es digna una vida con discapacidad. Por el contrario, esa no es una afirmación que asumiría el modelo social (mucho menos el modelo de la diversidad funcional) la dignidad o indignidad de una vida no tiene en sí misma que ver con que se tenga o no se tenga discapacidad. Reparemos que la discusión, ahora, se ha llevado al plano de una discusión valorativa, por ello importa la motivación que existe atrás de cada caso de selección genética.

¿Qué diría el modelo social de la selección genética que desecha embriones por discapacidad? Ya hemos dicho que admitiría este implante de embrión con sordera, pero, ¿admitiría que se desechen los embriones que tienen discapacidad? A los efectos del presente trabajo nos excede dar una respuesta acerca de si el diseño genético en sí mismo está mal o, por el contrario, es permisible y deseable. Sólo pretendo indagar qué sucede en el particular caso de embriones con discapacidad, indagando las respuestas desde cada uno de los modelos. Veamos: el modelo médico social admitiría el desecho de los embriones con discapacidad, en cambio - por la envergadura de la justificación moral que asume - la concepción de la diversidad funcional no lo admitiría.$^{13}$ Aquí la diferencia que existe entre estas últimas concepciones es sustancial. Siendo que la concepción de la diversidad funcional pregona el reconocimiento y condena toda actitud de menosprecio hacia la discapacidad, nunca admitiría el desecho. ${ }^{14} \mathrm{Y}$, para ello, no hace falta entrar en la discusión del status moral del embrión en absoluto. Considera que admitir dichas prácticas esconde de lleno un menosprecio hacia la discapacidad, sin entender que la discapacidad en sí misma no es mala, sino el entorno es que lo concibe así en razón de no valorar la diversidad.

En cambio, el modelo médico social podría asumir el desecho de embriones toda vez que su justificación y concepción valorativa de la discapacidad es más estrecha que el último modelo: no asume que la respuesta exclusiva sea erradicar el mal reconocimiento hacia la discapacidad, sino que considera que debemos erradicar las barreras sociales que se imponen a la discapacidad la cual se compone de cierto estado patológico perdurable en el tiempo en conjunto con la interacción que el entorno ofrece. Hasta tanto ese entorno no cambie, no se eliminen las barreras sociales, la discapacidad merecerá un especial trato. Pero, ¿por qué admitiría el desecho mientras permitiría ésta implantación de embrión con sordera? ¿Hemos entrado en una contradicción? No. Lo admite justamente porque asume que en sí mismo el caso particular de este hijo que nacerá con sordera será introducido en una familia que considera dicha diversidad como parte de sus hábitos, especial modo de vida, etc. y por ello deciden llevar adelante un proyecto de vida compatible con el desarrollo de su identidad auto percibido. Recordemos que, para este modelo, la

\footnotetext{
13 Claro está que se podría objetar que esta interpretación que realizo acerca de la postura de la concepción de la diversidad funcional respecto desecho de embriones con discapacidad es extrema. Alguien podría argumentar que los embriones no cuentan con status y, por tanto, entrar en la discusión acerca de porqué su protección independiente de la autonomía de personas gestantes es innecesaria. Sin embargo, y a los efectos del desarrollo argumental del presente artículo, esta aclaración se hace a los efectos de mostrar cómo asumir a priori que toda vida humana que se desarrollaría potencialmente con alguna diversidad funcional es indeseable, cuenta con una raíz discriminatoria a la discapacidad per se.

14 Nuestra ley, en su art. 14 establece que “(...) se entiende por embriones viables aquellos que pueden ser transferidos al útero de la mujer, en virtud de estudios previos que así lo determinan. Son embriones no viables o inviables aquellos que se han detenido en su desarrollo o que presentan alteraciones cromosómicas incompatibles con su posterior desarrollo, (...)”. No debemos confundir inviabilidad con discapacidad. La concepción de la diversidad funcional admitiría el desecho de embriones inviables, pero no así los embriones con discapacidad.
} 
dignidad o indignidad de una vida no tiene en sí misma que ver con que se tenga o no se tenga discapacidad. Así, prima facie, el desecho estaría permitido y el implante de embriones también, siempre y cuando la persona gestante decida llevar adelante una vida con discapacidad y pueda proveer de bienes necesarios para desarrollar una vida digna.

\section{Conclusión}

El presente trabajo pretendió esbozar una respuesta al dilema moral que aparece cuando unas pacientes pretenden implantar un embrión con sordera según las distintas concepciones de la discapacidad. Es un dilema moral toda vez que entran en contradicción dos principios bioéticos, a saber: el principio de autonomía del paciente, por un lado y el principio de no maleficencia, por el otro. ¿Cómo resuelve el dilema moral cada concepción de la discapacidad? Tanto la concepción de la prescindencia como la concepción médica entienden que no es permisible el accionar de las madres toda vez que se le generará un daño al niño que nacerá. Ello, por cuanto, carecer de salud es tener vida indigna y carecer de un sentido, como ser la audición, es indeseable. Así, estas concepciones ponen a la buena salud como un parámetro perfeccionista. Hacen valer, por tanto, el principio de no maleficencia por encima del de autonomía.

La concepción del modelo médico-social, por el contrario, haría primar al principio de autonomía por sobre el de no maleficencia. No por asumir que nunca una discapacidad en sí misma sea indeseable, sino porque en éste particular caso el contexto hará que la persona con discapacidad cuente con ciertos recursos para desenvolverse en una comunidad de personas con sordera y con ciertos bienes garantizados.

Por último, la concepción de la diversidad funcional diría, lisa y llanamente, que no existe dilema toda vez que no se pondría en juego el principio de no maleficencia: la discapacidad en sí misma no es negativa, sino que el entorno es la que menosprecia a personas con discapacidad. Esta concepción asume, así, el argumento que las madres han esbozado y permitiendo la fecundación de un embrión con sordera.

Ahora bien, por diversas razones de índole conceptual, pragmáticas y filosófico políticas defiendo la concepción médico-social que conserva el dato médico a la hora de conceptualizar discapacidad y, también, de abordar la discusión acerca de cómo brindar un trato justo a personas con discapacidad. Aclaro que el presente ejercicio reflexivo y argumental fue difícil desde el momento en que he reconocido que puede dicho modelo justificar ciertas prácticas eugenésicas, como ser el desecho de embriones por tener discapacidad. Pero, ¿cuáles son los efectos de que el modelo social conserve el dato médico a la hora de conceptualizar la discapacidad? Varias son las razones:

1. Cabe advertir que existen clases interactivas y clases no interactivas respecto al entorno (Hacking, 2001). Las clases típicamente interactivas son categorías, atributos y conductas humanas que pueden cambiar por efecto del bucle clasificatorio creado por la conciencia de dichas clases. Las clases no interactivas, por el contrario, no ven afectada su conducta y comportamiento por el hecho de ser categorizadas de una u otra manera. Ahora bien, ¿toda discapacidad es una clase interactiva? ¿Toda persona con discapacidad interactúa con el entorno, e incluso, con la categoría que el entorno impone? No. Pienso en caso de deficiencias que acarrean la carencia de lenguaje, como una parálisis cerebral compleja; o trastorno del espectro autista, entre otras. Aquí aparece una razón para conservar cuestiones médicas en torno al concepto mismo de discapacidad. Por ello, una concep- 
ción que priorice o entienda que la categoría de la discapacidad es exclusivamente social peca de no advertir que no toda discapacidad interactúa con el entorno.

2. Muchos de los reclamos en materia de discapacidad tienen que ver con el acceso a la salud, mejora de las condiciones de vida, etc. Aunque este es un argumento pragmático, no veo por qué no registrar que los propios reclamos del colectivo se traducen en conflictos con los Estados, Obras Sociales o Prepagas a la hora de hacer cumplir sus derechos.

3. Considero que no tener en cuenta el dato médico puede arrastrar un problema en el campo filosófico político. Si queremos lograr una teoría de la justicia que sea comprehensiva de la discapacidad, no podemos obviar el dato relevante acerca de su estado de salud, sino nos vemos tentados a dar respuestas similares a todos los casos de injusticia social: pobreza, género, etc. Y, por el contrario, lo que pretendo defender es que la discapacidad, por el abordaje que reciben en nuestras sociedades actuales, es una específica y particular manera de sufrir injusticia social, por exclusivo motivo de cómo la diversidad genera desigualdades pero, también, por la carencia de bienes médicos y recursos recuerdos para afrontar ciertos gastos relativos a la calidad de vida a raíz de ciertas dificultades y dolores que traen aparejados ciertos estados de salud.

\section{REFERENCIAS BIBLIOGRÁFICAS}

- Alemany, M. (2018). Igualdad y diferencia en relación con las personas con discapacidad. (Una crítica a la Observación Na (2014) del Comité (UN) de los derechos de las personas con discapacidad). Anales de la Cátedra Francisco Suárez 52, pp. 201-222

- Beauchamp, T. L. - Childress, J. F. (1999) Principios de ética biomédica (4 edición), Masson S.A: Barcelona.

- Brock, D.W (1994) Life and Death, Cambridge University Press.

- Díaz García, A (2009) La ética de la virtud y la bioética Revista Colombiana de Bioética, vol. 4, núm. 1, enero-junio, 2009, pp. 93-128 Universidad El Bosque Bogotá, Colombia. Recuperado el 10/07/2020 de www.redalyc.org/

- Eroles, C. (2008). Diccionario latinoamericano de bioética. Dir. Juan Carlos Tealdi. -Bogotá: UNESCO - Red Latinoamericana y del Caribe de Bioética: Universidad Nacional de Colombia, 2008.

- Hacking, I. (2001) ¿La construcción social de qué? Editorial Paidós, Buenos Aires;

- Luna, F., (2013) "Infertilidad en Latinoamérica. En busca de un nuevo modelo". Revista de Bioética y Derecho, núm. 28, mayo 2013, p. 33-47.

- Morales Aguilera, P. y Vallés González, B. (2013), B. Discapacidad y reconocimiento: reflexiones desde el prisma de Axel Honneth. Revista Dilemata, Año 5, 2013, P. 198-208. Recuperado el 06/06/2019 de www.revistes.ub.edu;

- Palacios, A. (2008). El modelo social de discapacidad: origenes, caracterizacion y plasmacion en la Convención Internacional sobre los Derechos de las Personas con discapacidad. Madrid: Cinca.

- Pfeiffer, M. L (2001) Acerca del bios. Una reflexión bioética. En HOOFT P, CHAPARRO E 
y SALVADOR S (coord.) VII Jornadas Argentinas y Latinoamericanas de Bioética, Suárez, Mar del Plata.

- Romañach J. (2008). El modelo de la diversidad: una herramienta para la emancipación y la plena de ciudadanía de las personas con diversidad funcional (discapacidad). Recuperado el 09/06/202019 en http://www.ub.edu/demoment

- Ross, W.D (2002) The right and the good, Clarendon Press: Oxford.

- Sandel, M. (2007) Contra la perfección. La ética en la era de la ingeniería genética. Barcelona: Marbot.

- Singer, P. (2001) Killing Babies Isn't Always Wrong. The Spectator (September 16, 1995): 20-22.

- Thomson, J. J (2001) “Una defensa del aborto”, en Margarita Valdés, Controversias sobre el Aborto, México, Fondo de Cultura Económica Universidad Nacional Autónoma de México, Instituto de Investigaciones Filosóficas, 2001.

- Valdés, E. (2015) Haciendo más práctico el principialismo. La importancia de la especificación en bioética. Rev. Bioética y Derecho N³5, Barcelona. Recuperado el 08/07/2020 de http://scielo.isciii.es/

-Warren, M. A. (1995) "Sobre el status moral y legal del aborto" en Luna, Florencia y SaIles, Arleen L. F., Decisiones de vida y muerte. Eutanasia, aborto y otros temas de ética médica, Buenos Aires, Sudamericana, 1995. 